\title{
Oriented growth of thin films of samarium oxide by MOCVD
}

\author{
K SHALINI and S A SHIVASHANKAR* \\ Materials Research Centre, Indian Institute of Science, Bangalore 560 012, India
}

MS received 31 December 2004

\begin{abstract}
Thin films of $\mathrm{Sm}_{2} \mathrm{O}_{3}$ have been grown on $\mathrm{Si}(100)$ and fused quartz by low-pressure chemical vapour deposition using an adducted $\beta$-diketonate precursor. The films on quartz are cubic, with no preferred orientation at lower growth temperatures $\left(\sim 550^{\circ} \mathrm{C}\right)$, while they grow with a strong (111) orientation as the temperature is raised $\left(\right.$ to $\left.625^{\circ} \mathrm{C}\right)$. On $\mathrm{Si}(100)$, highly oriented films of cubic $\mathrm{Sm}_{2} \mathrm{O}_{3}$ at $625^{\circ} \mathrm{C}$, and a mixture of monoclinic and cubic polymorphs of $\mathrm{Sm}_{2} \mathrm{O}_{3}$ at higher temperatures, are formed. Films grown on either substrate are very smooth and fine-grained. Infrared spectroscopic study reveals that films grown above $600^{\circ} \mathrm{C}$ are free of carbon.
\end{abstract}

Keywords. MOCVD; thin films; $\beta$-diketonate; samarium oxide; gate dielectric.

\section{Introduction}

As complementary metal oxide semiconductor (CMOS) downscaling moves further, the physical thickness of the gate dielectric layer rapidly decreases, which can cause excessive gate leakage currents due to direct tunnelling. This necessitates the use of materials with a higher dielectric constant to replace $\mathrm{SiO}_{2}(\varepsilon=3 \cdot 9)$, the current gate dielectric. Such an alternative material may be made physically thicker, while providing equivalent capacitance. Oxide materials, especially those in amorphous form and possessing good thermal and chemical stability, as well as compatibility with CMOS integration schemes, are of particular interest. Rare earth oxides are examples of such materials, many of which are characterized by high values of dielectric constant (8-20), high resistivity, and chemical and thermal stability. Even so, silicon MOS structures with rare earth oxides have been investigated only recently (Ono and Katsumata 2001; Mikhelashvili et al 2002). Very thin layers of rare earth oxides, such as $\mathrm{Sm}_{2} \mathrm{O}_{3}$ and epitaxial $\mathrm{Gd}_{2} \mathrm{O}_{3}$, grown by thermal evaporation techniques, have been proposed recently as the gate dielectric material for very large scale integrated (VLSI) circuits of the future, in both Si and GaAs technologies (Rozhkov et al 1998; Hong et al 1999). A recent report concerns the possible use of $\mathrm{La}_{2} \mathrm{O}_{3}$ grown by metalorganic chemical vapour deposition (MOCVD) as gate dielectric in Si CMOS (Jun et al 2002). In earlier reports from our laboratory (Singh et al 2003, 2004), the suitability of erbium oxide and gadolinium oxide thin films as high-k dielectrics for VLSI applications has been demonstrated.

The chemical vapour deposition (CVD) technique has several advantages over other physical processes, such

*Author for correspondence (shivu@mrc.iisc.ernet.in) as the capability for large area deposition, excellent compositional control and film uniformity, high film densities and deposition rates. We have, therefore, undertaken the growth of samarium oxide by MOCVD. However, a critical issue for successful MOCVD is the availability of molecular precursors having high volatility and stability, appropriate reactivity, and permitting straightforward synthesis.

As the inorganic salts of the lanthanides, such as their halides, are insufficiently volatile, coordination complexes of lanthanides have been explored as precursors for the MOCVD of lanthanide-containing oxides. These complexes should preferably be monomeric in order to have optimal vapour pressures (Hogerheide et al 1996). Thus, the $\beta$-diketonates of yttrium and the rare earth metals, which are subliming crystalline compounds, have often been used as precursors in the MOCVD of thin films of superconducting cuprates (Berry et al 1990). As $\beta$-diketonates are coordination complexes containing bidentate ligands, they are often thermally stable and can be easily prepared for a wide range of metals (Mehrotra et al 1978). Yet, such complexes of lanthanides have drawbacks, such as a large amount of residue left in their vapourisers and their propensity to oligomerize when exposed to (and stored in) air (Drake et al 1993a). Hence, the availability of monomeric, thermally stable, volatile, and water-free lanthanide complexes is of practical relevance, given the lack of MOCVD precursors with suitable properties. The hydrated $\beta$-diketonate complexes are not suitable, as they tend to polymerize or hydrolyse at high temperatures $\left(>200^{\circ} \mathrm{C}\right.$ ) needed for vapourization (Sievers and Sadlowski 1978).

Several lanthanide diketonate adducts with polyethers (Drake et al 1993a,b; Bradley et al 1994; Baxter et al 1995) and lanthanide ketoiminates (Belot et al 1999) have been developed with a view to using them as precursors for the 
deposition of thin films of lanthanide-containing oxides. Some of these adducts exhibit improved properties over the $\beta$-diketonates, in terms of thermal stability and volatility, and are of potential interest for application as MOCVD precursors. But, the synthesis of these precursors requires stringent conditions. Therefore, we have taken the alternative approach of using a non-fluorinated lanthanide pentadionates and improving upon their thermal stability by adducting them with nitrogen donor ligands, viz. 1,10phenanthroline.

Specifically, we report in this paper the synthesis and thermal characterization of tris(2,4-pentadionato)(1,10phenanthroline)samarium(III) $\left[\mathrm{Sm}(\mathrm{pd})_{3} \cdot\right.$ Phen]. The growth of thin films of $\mathrm{Sm}_{2} \mathrm{O}_{3}$ using this precursor has been carried out as a case study, in order to show that the adducted complexes can be used successfully as precursors in the growth of thin crystalline oxide films at relatively low temperatures by MOCVD.

\section{Experimental}

\subsection{Synthesis of tris(2,4-pentadionato) $\left(1,10\right.$-phenanthroline) samarium [Sm $(\mathrm{pd})_{3}$.Phen]}

Commercially available (AR grade) $\mathrm{NaOH}$, ammonia, hydrochloric acid, 2,4-pentadione, and 1,10-phenanthroline were used for synthesis, without further purification. High purity (99.99\%) $\mathrm{Sm}_{2} \mathrm{O}_{3}$ powder was calcined at high temperature to remove carbonate and $\mathrm{SmCl}_{3}$ was prepared from it. The synthesis of the adducted complex involves the addition of ethanolic solution of 2,4-pentadione to an aqueous solution of samarium chloride in the presence of sodium hydroxide, followed by the addition of ethanolic 1,10-phenanthroline solution. After completion of the reaction, the product formed (yield $\cong 85 \%$ ) was filtered, washed with water, and dried. Further purification of the complex was accomplished by recrystallizing the crude product from an aqueous ethanolic solution.

\subsection{Precursor characterization}

The adducted complex was characterized by (a) infrared spectroscopy (which shows bands at $1595 \mathrm{~cm}^{-1}$ and $1516 \mathrm{~cm}^{-1}$ for $\mathrm{C}=\mathrm{C}$ and $\mathrm{C}=\mathrm{O}, 850 \mathrm{~cm}^{-1}$ and $729 \mathrm{~cm}^{-1}$ for aromatic C-H out-of-plane bending, and at $398 \mathrm{~cm}^{-1}$ due to the Sm-O bond), (b) mass spectrometry $(\mathrm{m} / \mathrm{z}=530$ for $\mathrm{Sm}(\mathrm{pd})_{2} \cdot \mathrm{Phen}, 450$ for $\mathrm{Sm}(\mathrm{pd})_{3}, 350$ for $\mathrm{Sm}(\mathrm{pd})_{2}, 251$ for Smpd), (c) elemental analysis [C 51.46 (51.64), H 4.61 (4.62), N 4.36 (4.46)], and (d) single crystal X-ray diffraction (Urs et al 2001), in order to confirm its formation. Simultaneous thermogravimetry and differential thermal analysis (TG/DTA) of the complex was carried out at atmospheric pressure in flowing nitrogen to examine the volatility and stability of the complex.

\subsection{Thin film deposition and characterization}

Thin films of $\mathrm{Sm}_{2} \mathrm{O}_{3}$ were deposited in a horizontal, hotwall reactor built in-house, which consists of a fused quartz tube of diameter, $55 \mathrm{~mm}$ and length, $65 \mathrm{~cm}$. A series of substrates [fused quartz or $\mathrm{Si}(100)$ ] was placed parallel to the reactor axis so that depositions at different temperatures $\left(450-675^{\circ} \mathrm{C}\right)$ could be carried out in a single run, using the natural temperature gradient in the CVD reactor. In such an arrangement, the thickness of the films deposited varies with the position of the substrate, and is lower on the substrates placed downstream of precursor flow, due to the reduced precursor flux at these locations. High purity argon (20-100 sccm) was used as the carrier gas, while the reactive gas (20-250 sccm) employed was high purity oxygen. The precursor, $\operatorname{Sm}(\mathrm{pd})_{3}$. Phen, in finely powdered form, was kept in an aluminium boat placed at one end of the reactor tube, and maintained at a temperature in the range $200-250^{\circ} \mathrm{C}$. The total pressure in the reactor was maintained at 2 Torr. The average thickness of the film on a given substrate was estimated using the weight gain method. The $\mathrm{Sm}_{2} \mathrm{O}_{3}$ films were characterized for their crystallinity by X-ray diffraction (XRD), and for surface morphology by scanning electron microscopy (SEM) and atomic force microscopy (AFM). The optical transmittivity of the films was studied by Fourier transform infrared (FTIR) spectroscopy.

\section{Results and discussion}

\subsection{Thermogravimetric and differential thermal analysis $(T G / D T A)$ of $\operatorname{Sm}(p d)_{3}$.Phen}

The schematic molecular structure of $\mathrm{Sm}(\mathrm{pd})_{3}$.Phen is shown in figure 1(a). The simultaneous thermogravimetry/ differential thermal analysis (TG/DTA) of the complex, carried out at atmospheric pressure, is shown in figure 1(b). It should be noted here that the weight loss trend as a function of temperature is the same when the thermal analysis is conducted at different pressures, i.e. the trend is the same at atmospheric pressure at which the TG/DTA is carried out and at lower pressures at which the complex is actually vapourized in the CVD process. In fact, the lower pressure in the vapourizer prevailing during the CVD process ensures greater vapourization of the complex at a given temperature. The TG curve shown in figure $1(\mathrm{~b})$ is flat at low temperatures, showing no weight loss up to $225^{\circ} \mathrm{C}$. Above this temperature, the complex loses its weight slowly up to $330^{\circ} \mathrm{C}$ and, then, to a substantial degree between $\sim 330^{\circ} \mathrm{C}$ and $355^{\circ} \mathrm{C}$. The weight loss again becomes gradual at higher temperatures until a residual weight of $\sim 50 \%$ is attained. This residual weight is higher than that expected for either the oxide ( $c a$. $27.8 \%$ ) or the carbonate ( $c a .38 \cdot 3 \%$ ) of Sm. No attempt was made to analyse the composition of the residue. The 
DTA pattern shows a sharp endotherm at $347^{\circ} \mathrm{C}$, corresponding to the step in the TG curve. This is attributed to the enhanced sublimation of the complex (Fahlman and Baron 2000). It was also verified through a separate TGA run that there was no change in the thermal behaviour of the complex even after storing it for one year in dry nitrogen. This indicates its high thermal stability during storage - an important and desirable characteristic of a CVD precursor.

\section{$3.2 \mathrm{X}$-ray diffraction study of $\mathrm{Sm}_{2} \mathrm{O}_{3}$ films}

The XRD patterns of the $\mathrm{Sm}_{2} \mathrm{O}_{3}$ films grown on fused quartz substrates at different temperatures are shown in figure 2 . The patterns indicate that the films comprise the cubic phase of $\mathrm{Sm}_{2} \mathrm{O}_{3}$ at all the temperatures of growth employed here. The films grown at temperatures up to $540^{\circ} \mathrm{C}$ are $\mathrm{X}$-ray amorphous, with crystallinity developing and increasing when the growth temperature is raised beyond $540^{\circ} \mathrm{C}$. The film grown at a temperature of $575^{\circ} \mathrm{C}$ is polycrystalline, displaying peaks corresponding to both (222) and (220) reflections [JCPDS file No. 15-0813]. As the temperature is increased, the intensity of the (220) reflection decreases simultaneously with an increase in the intensity of the (222) reflection, indicating the tendency for textured growth as the substrate temperature is raised. The XRD patterns of the film grown at $625^{\circ} \mathrm{C}$

(a)
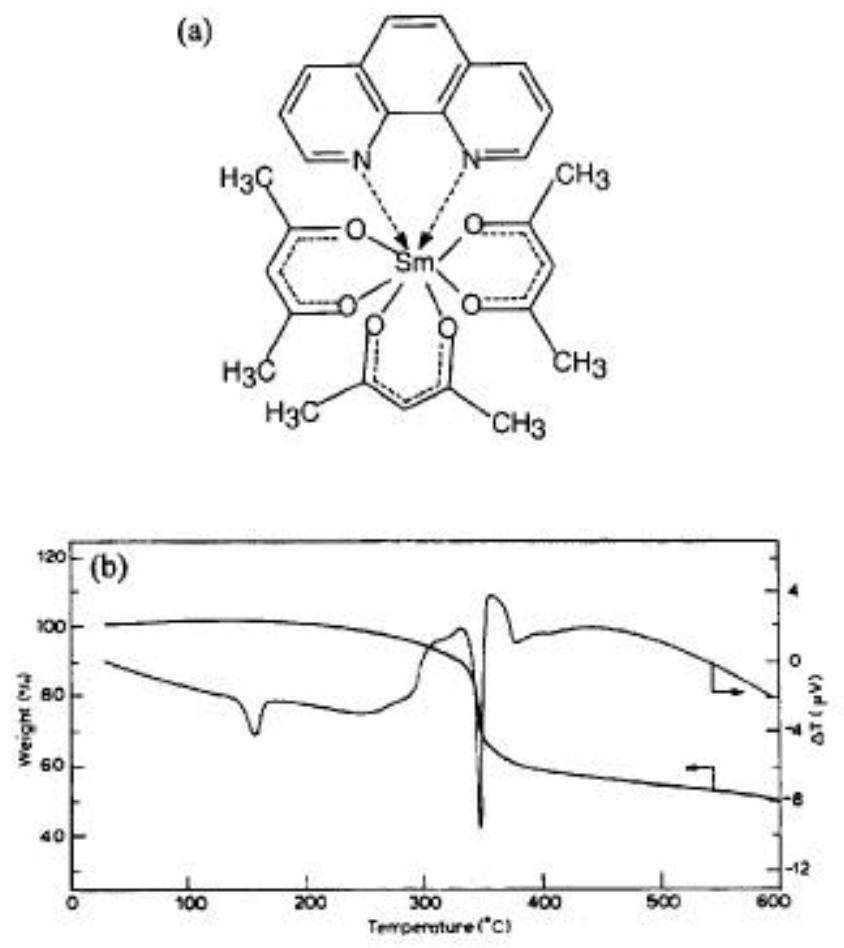

Figure 1. (a) Schematic molecular structure and (b) TG/DTA pattern of $\operatorname{Sm}(\mathrm{pd})_{3} \cdot$ Phen. show only the (222) reflections of high intensity, and the weaker (444) reflection.

The XRD patterns of $\mathrm{Sm}_{2} \mathrm{O}_{3}$ films grown on $\mathrm{Si}(100)$ at different temperatures are shown in figure 3 . The films grown on $\mathrm{Si}(100)$ are $\mathrm{X}$-ray amorphous up to a growth temperature of $\sim 540^{\circ} \mathrm{C}$. Above this temperature, the films are polycrystalline, comprising cubic $\mathrm{Sm}_{2} \mathrm{O}_{3}$. As the growth temperature is raised, the films steadily acquire a preferred orientation parallel to (111) and, at a temperature of $625^{\circ} \mathrm{C}$, the XRD pattern consists of a strong (222) reflection, to the exclusion of peaks corresponding to all other $(h k l)$ values. The growth of strongly oriented cubic $\mathrm{Sm}_{2} \mathrm{O}_{3}$ on $\mathrm{Si}(100)$ may be understood by considering the lattice match between the two. The lattice constant of cubic $\mathrm{Sm}_{2} \mathrm{O}_{3}$ is $1.0927 \mathrm{~nm}$, which matches closely with twice that of $\mathrm{Si}$, whose lattice constant is $0.543088 \mathrm{~nm}$ (i.e. lattice mismatch $=0.6 \%$ ). With a further increase in the growth temperature to $660^{\circ} \mathrm{C}$, the monoclinic phase of $\mathrm{Sm}_{2} \mathrm{O}_{3}$ is formed along with the cubic phase, as indicated clearly by the powder XRD patterns of figure 3 . The formation of the monoclinic phase at higher temperatures is consistent with the (binary) phase diagram of $\mathrm{Sm}_{2} \mathrm{O}_{3}$, wherein the monoclinic phase is preferred at higher temperatures, the cubic phase being favoured at lower temperatures.

It is to be noted that the growth of cubic $\mathrm{Sm}_{2} \mathrm{O}_{3}$ is characterized by a strong (111)-orientation, both on the single crystalline $\mathrm{Si}(100)$, as well as on the fused quartz substrate, which has no crystalline order. Indeed, at $625^{\circ} \mathrm{C}$, the (222) reflection from the film on the amorphous fused quartz substrate is stronger than from the film on $\mathrm{Si}(100)$, the thickness of the two films being comparable $(\sim 120 \mathrm{~nm})$. While strongly oriented growth on $\mathrm{Si}(100)$ is to be ex-

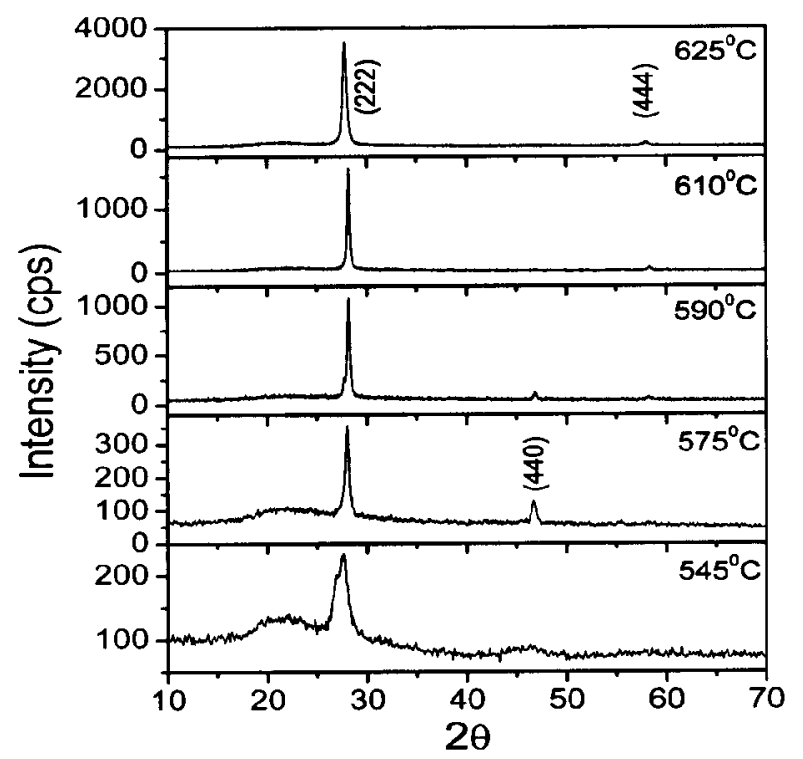

Figure 2. XRD patterns of $\mathrm{Sm}_{2} \mathrm{O}_{3}$ films grown on fused quartz at different temperatures. 
pected because of the close lattice constant match with cubic $\mathrm{Sm}_{2} \mathrm{O}_{3}$, strongly oriented growth on fused quartz is surprising. This may be understood on the basis of the possibility that growth occurs in such a way as to minimize the surface energy (Bauer 1962; Smith and Flanders 1978; Yoon et al 1999). In such growth on smooth amorphous substrates, that orientation of the crystalline film is preferred which has the largest atomic density. This happens to be the (111) orientation for the cubic material, $\mathrm{Sm}_{2} \mathrm{O}_{3}$. It is possible that such oriented growth of an oxide film (apparently not observed frequently, as evidenced by the scarcity of reports in the literature) is aided by the presence of oxygen in the substrate. This is evidenced by the strong adherence of the $\mathrm{Sm}_{2} \mathrm{O}_{3}$ film to the fused quartz substrate, despite the smoothness of its surface. Film growth with preferred orientation may also be aided by the MOCVD process, wherein metal complexes with built-in metal-oxygen bonds, as in this case (figure 1a), are employed as precursors. Similarly, strong preferred orientation has been observed in thin films of $\mathrm{VO}_{2}$ grown by MOCVD on glass substrates (Sahana et al 2002). The poorer orientation of the $\mathrm{Sm}_{2} \mathrm{O}_{3}$ film on $\mathrm{Si}(100)$, compared to growth on fused quartz, may be due to the native oxide present on the silicon surface. Even though the lattice match between $\mathrm{Si}$ and $\mathrm{Sm}_{2} \mathrm{O}_{3}$ is excellent, the oxygenrich ambient of the CVD reactor does not permit a 'fresh', native oxide-free $\mathrm{Si}(100)$ to be presented for the growth of $\mathrm{Sm}_{2} \mathrm{O}_{3}$.

\subsection{Scanning electron microscopy of $\mathrm{Sm}_{2} \mathrm{O}_{3}$ films}

The SEM analysis of the films grown on fused quartz shows the film surface to be very smooth, up to a growth

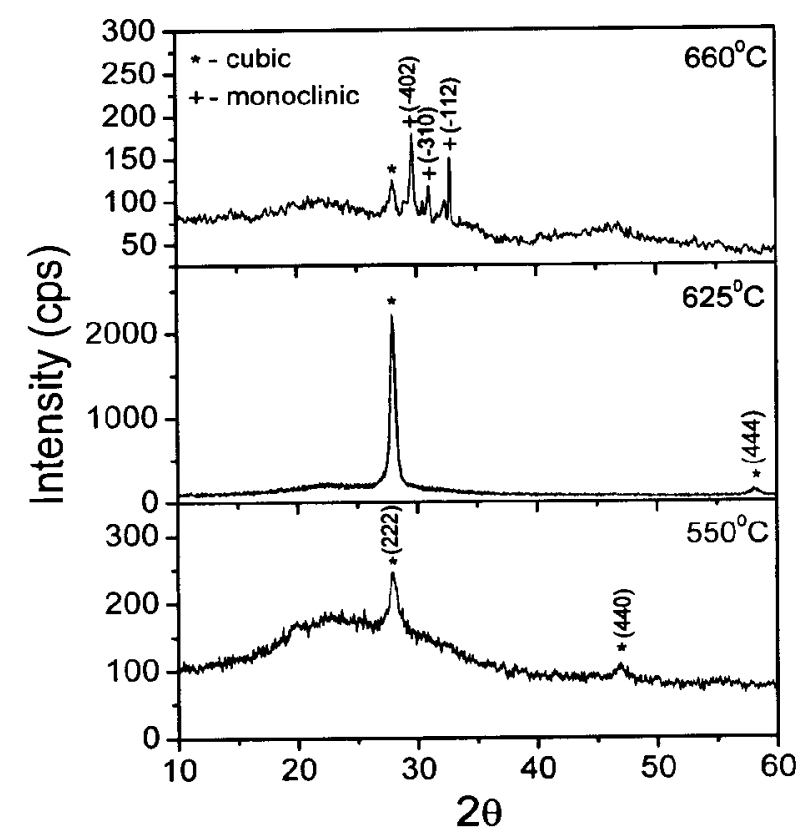

Figure 3. XRD patterns of $\mathrm{Sm}_{2} \mathrm{O}_{3}$ films grown on $\mathrm{Si}(100)$ at different temperatures. temperature of $540^{\circ} \mathrm{C}$. This observation is consistent with the XRD data, wherein it is observed that the films grown below this temperature are amorphous in nature. As the growth temperature is raised, the films exhibit a very fine-grained morphology, as can be seen from the SEM micrograph of the film grown at $625^{\circ} \mathrm{C}$ (figure $4(\mathrm{a})$ ). The grain size of the films deposited at $550^{\circ} \mathrm{C}$ is $\sim 100 \mathrm{~nm}$, with the grain size increasing to $\sim 200 \mathrm{~nm}$ as the growth temperature is raised to $625^{\circ} \mathrm{C}$.

As in the case of the films on fused quartz, the surface morphology of the $\mathrm{Sm}_{2} \mathrm{O}_{3}$ films grown on $\mathrm{Si}(100)$ is very smooth and featureless up to the substrate temperature of $540^{\circ} \mathrm{C}$, indicating that the films are amorphous. As the growth temperature is increased further to $625^{\circ} \mathrm{C}$, the grains orient themselves in a preferred crystallographic direction; this texture is evident in the SEM micrograph shown in figure 4(b). With a further increase in the growth temperature, the morphology again becomes smooth and devoid of much feature. This is consistent with the XRD pattern wherein the formation of the monoclinic phase, along with the cubic phase, is in evidence at this temperature. The simultaneous nucleation of the two polymorphs may be expected to impede the development of a preferred orientation for either of the two phases.
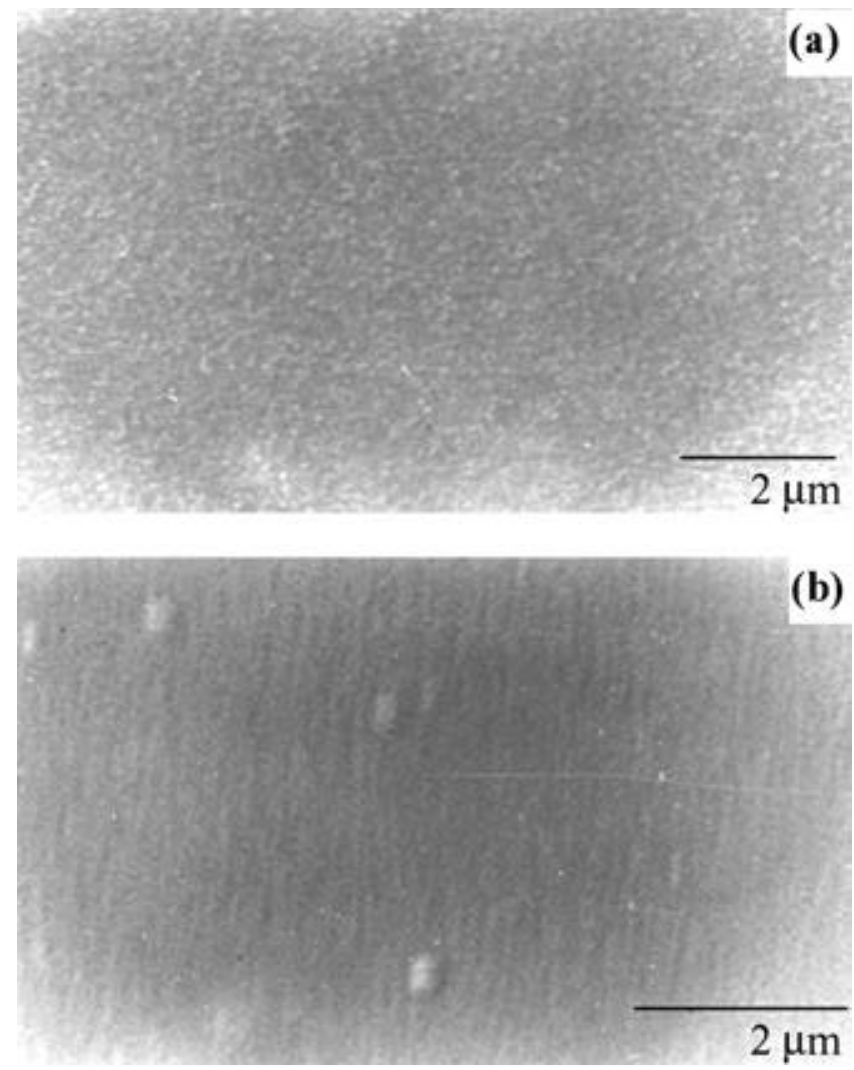

Figure 4. SEM micrograph of the $\mathrm{Sm}_{2} \mathrm{O}_{3}$ film grown at $625^{\circ} \mathrm{C}$ on (a) fused quartz and (b) $\mathrm{Si}(100)$. 


\subsection{Atomic force microscopy of $\mathrm{Sm}_{2} \mathrm{O}_{3}$ films}

The surface morphology of the $\mathrm{Sm}_{2} \mathrm{O}_{3}$ films grown on fused quartz and $\mathrm{Si}(100)$ substrates was examined also by atomic force microscopy. Figure 5(a) shows the AFM micrograph of the cubic $\mathrm{Sm}_{2} \mathrm{O}_{3}$ films grown on fused quartz at $625^{\circ} \mathrm{C}$. The AFM micrographs of films grown on $\mathrm{Si}(100)$ at $625^{\circ} \mathrm{C}$ and $660^{\circ} \mathrm{C}$ are shown in figures $5(\mathrm{~b})$ and $5(\mathrm{c})$. The morphology of the films grown at $\sim 625^{\circ} \mathrm{C}$ on both the substrates, showing faceted grains, indicates that the films are well crystallized, and display a preferred orientation. This is consistent with the XRD pattern wherein only the peak corresponding to the (222) reflection of cubic $\mathrm{Sm}_{2} \mathrm{O}_{3}$ is seen. Figure 5(c) shows AFM
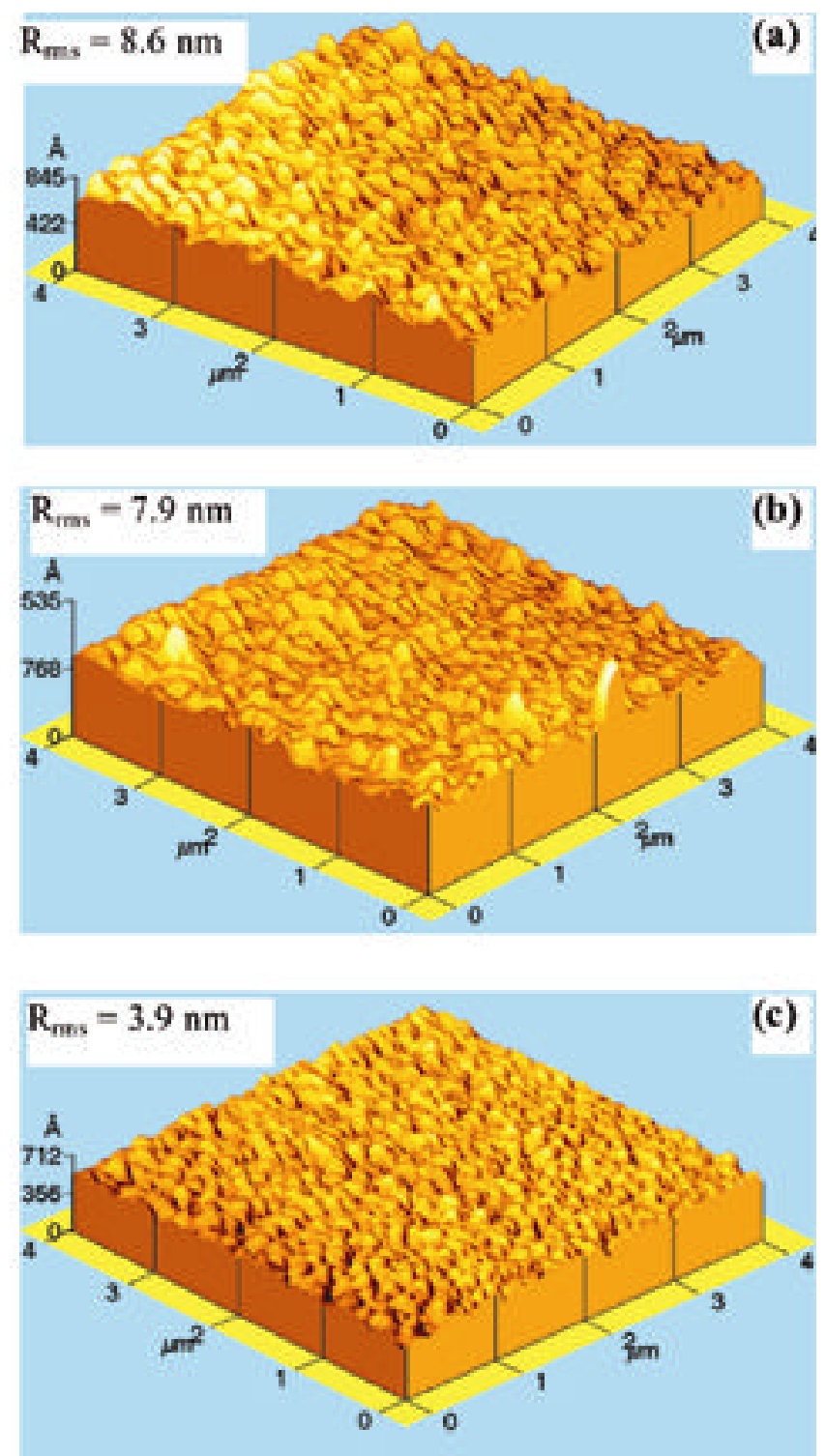

Figure 5. AFM micrographs of the $\mathrm{Sm}_{2} \mathrm{O}_{3}$ film grown on (a) fused quartz at $625^{\circ} \mathrm{C},(\mathbf{b}) \mathrm{Si}(100)$ at $625^{\circ} \mathrm{C}$, and (c) $\mathrm{Si}(100)$ at $660^{\circ} \mathrm{C}$. micrograph of the film grown at $660^{\circ} \mathrm{C}$ on $\mathrm{Si}(100)$. The morphology is clearly different from that of the films shown above consisting of the cubic phase. This is again consistent with the XRD data, wherein we observe that the film grown at this temperature consists of $\mathrm{Sm}_{2} \mathrm{O}_{3}$ grains of the monoclinic phase as well as the cubic phase. The AFM data quantify the roughness (smoothness) of the films grown on two different substrates at different temperatures. The RMS roughness of the film on fused quartz is $8.6 \mathrm{~nm}$ (over an area of $4 \mu \mathrm{m}$ by $4 \mu \mathrm{m}$ ) for the film of thickness $\sim 120 \mathrm{~nm}$ grown at $625^{\circ} \mathrm{C}$. The roughness is similar $(7.9 \mathrm{~nm})$ for the film grown on $\mathrm{Si}(100)$ at the same temperature. However, the film grown on $\mathrm{Si}(100)$ at $660^{\circ} \mathrm{C}$ is apparently smoother, with a RMS roughness of only $3.9 \mathrm{~nm}$. This reduced roughness might be attributed to the simultaneous nucleation and growth of grains of both the cubic and monoclinic phases. This reduces the tendency for a strong (111) orientation, thus making the film less faceted and smoother. It is found that the $\mathrm{Sm}_{2} \mathrm{O}_{3}$ films grown on $\mathrm{Si}(100)$ even at rather elevated temperatures are sufficiently smooth to be useful as the alternate gate dielectric in CMOS VLSI devices.

\subsection{Optical properties of $\mathrm{Sm}_{2} \mathrm{O}_{3}$ films}

The optical transmittance in the infrared region of the samarium oxide films grown on $\mathrm{Si}(100)$ at different temperatures is shown in figure 6 . The films grown at temperatures lower than $560^{\circ} \mathrm{C}$ show two strong but broad bands at $\sim 1500 \mathrm{~cm}^{-1}$ and $\sim 1400 \mathrm{~cm}^{-1}$, indicating the pre-

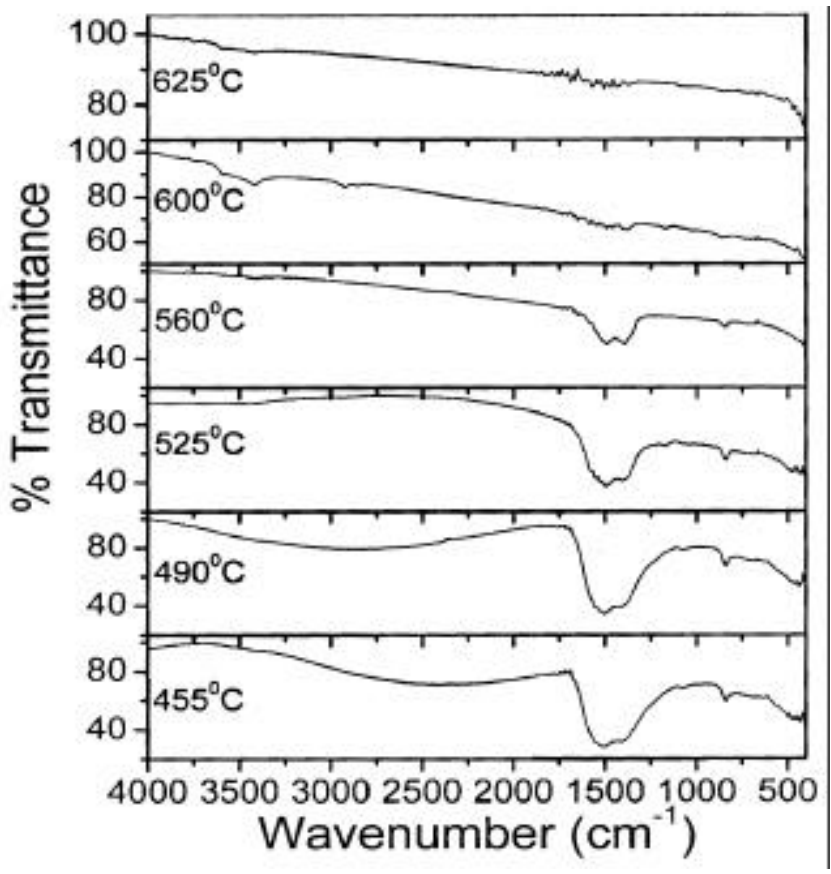

Figure 6. FTIR spectra of the $\mathrm{Sm}_{2} \mathrm{O}_{3}$ films grown on $\mathrm{Si}(100)$ at different temperatures. 
sence of the metal carbonate in the film. In addition, there are two more bands, a very broad band at $\sim 1070 \mathrm{~cm}^{-1}$ and another one at $840 \mathrm{~cm}^{-1}$, again corresponding to the carbonate. These four bands clearly indicate the presence of carbonate in the film. As deposited, the films grown at these lower temperatures are blackish in appearance, unlike the ones grown at higher temperatures, which were colourless and transparent. This suggests that films grown at lower temperatures contain carbon (from the precursor), which, on exposure to atmospheric air, leads to the metal carbonate. The films grown at higher temperatures do not show any signature of the carbonate. There is a broad band at $3410-3420 \mathrm{~cm}^{-1}$ for films grown at temperatures lower than $625^{\circ} \mathrm{C}$, showing the presence of moisture. As the growth temperature increases, the bands due to the carbonate moiety and moisture disappear, suggesting that films grown under these temperatures might be suitable as the gate dielectric in MOS circuits.

\section{Conclusions}

The adducted rare earth $\beta$-diketonate complex, $\operatorname{Sm}(\mathrm{pd})_{3}$. Phen, has been synthesized and characterized for its formation. Thermal analysis of the complex has been carried out to test its stability and suitability as CVD precursor. Thin films of samarium oxide, $\mathrm{Sm}_{2} \mathrm{O}_{3}$, have been grown using the complex as precursor, at different temperatures on fused quartz and $\mathrm{Si}(100)$. It is found that the films are highly crystalline and consist of the cubic phase at lower temperatures. With increase in the growth temperature, the films acquire a preference for the (111) orientation on both the substrates. The film grown on $\mathrm{Si}(100)$ substrate at $625^{\circ} \mathrm{C}$ is strongly oriented. This can be understood because of the very small lattice mismatch $(0.6 \%)$ between cubic $\mathrm{Sm}_{2} \mathrm{O}_{3}$ and $\mathrm{Si}(100)$. The film grown on fused quartz at the same temperature is also highly oriented in the (111) direction. This may be interpreted as being driven by the minimization of surface energy. As the growth temperature is increased, on $\mathrm{Si}(100)$, the monoclinic $\mathrm{Sm}_{2} \mathrm{O}_{3}$ is formed, in addition to the cubic phase. The surface morphology of the films grown at different temperatures as seen by SEM and AFM is very smooth and continuous. The IR spectra of the films grown on $\mathrm{Si}(100)$ at different growth temperatures show the presence of metal carbonate and moisture impurities at low growth temperatures and, as the growth temperature is increased, the bands due to these impurities vanish. These findings suggest that it is possible to grow high quality thin films of rare earth oxides by MOCVD, using the phenanthroline adducts of pentadionate complexes.
The growth of thin films of other rare earth oxides by MOCVD, using similar adducted pentadionate complexes, suggests itself.

\section{Acknowledgement}

One of the authors (KS) thanks CSIR, New Delhi, for the grant of a research fellowship.

\section{References}

Baxter I, Drake S R, Hursthouse M B, Abdul Malik K M, McAleese J, Otway D J and Plakatouras J C 1995 Inorg. Chem. 341384

Bauer E, 1962 Trans. 9th vac. sym. AVS (ed.) G H Bancroft (New York: Macmillan) p. 35

Belot J A, Wang A, McNeely R J, Liable-Sands L, Rheingold A L and Marks T J 1999 Chem. Vap. Deposition 565

Berry A D, Holm R T, Fatemi M and Gaskill D K 1990 J. Mater. Res. 51169

Bradley D C, Chudzynska H, Hursthouse M B and Motevalli M 1994 Polyhedron 137

Drake S R, Lyons A, Otway D J, Slawin A M Z and Williams D J 1993 J. Chem. Soc. Dalton Trans. 2379

Drake S R, Hursthouse M B, Malik K M A, Miller S A S and Otway D J 1993 Inorg. Chem. 324464

Fahlman B D and Baron A R 2000 Adv. Mater. Opt. Electron. 10223

Hogerheide M P, Boersma J and van Koten G 1996 Coord. Chem. Rev. 15587

Hong M, Kwo J, Kortan A R, Mannaerts J P and Sergent A M 1999 Science $\mathbf{2 8 3} 1897$

Jun J H, Wang C H, Won D J and Choi D J 2002 J. Korean Phys. Soc. 41998

Mehrotra R C, Bohra R and Gaur D P 1978 Metal $\beta$-diketonates and allied derivatives (New York: Academic Press) Ch. 2

Mikhelashvili V, Eisenstein G and Edelmann F 2002 Appl. Phys. Lett. 802156

Ono H and Katsumata T 2001 Appl. Phys. Lett. 781832

Rozhkov V A, Trusova A Y and Berezhnoy I G 1998 Thin Solid Films $\mathbf{3 2 5} 151$

Sahana M B, Subbanna G N and Shivashankar S A $2002 J$. Appl. Phys. 926495

Sievers R E and Sadlowski J E 1978 Science 201217

Singh M P, Thakur C S, Shalini K, Bhat N and Shivashankar S A 2003 Appl. Phys. Lett. 832889

Singh M P, Thakur C S, Shalini K, Banerjee S, Bhat N and Shivashankar S A 2004 J. Appl. Phys. 965631

Smith H I and Flanders D C 1978 Appl. Phys. Lett. 32349

Urs U K, Shalini K, Cameron T S, Shivashankar S A and Guru Row T N 2001 Acta Crystallogr. E57 m457

Yoon J G, Oh H K and Lee S J 1999 Phys. Rev. B60 2839 